\title{
Successful repair of wide traumatic rectal perforation using over-the-scope clip
}

\section{다)(1) $\Theta($}

Authors

Mauro Manno, Simona Deiana, Tommaso Gabbani, Sara Vavassori, Laura Ottaviani, Paola Soriani

Institution

Ramazzini Hospital, Gastroenterology and Digestive

Endoscopy, Carpi (Modena), Italy

submitted 6.8.2019

accepted after revision 30.9.2019

\section{Bibliography}

DOI https://doi.org/10.1055/a-1093-0778 |

Endoscopy International Open 2020; 08: E548-E549

(c) Georg Thieme Verlag KG Stuttgart · New York eISSN 2196-9736
Corresponding author

Mauro Manno, Ramazzini Hospital - Gastroenterology and

Digestive Endoscopy, Via Guido Molinari 2 Carpi , Modena 41012, Italy

Fax: +059659250

m.manno@ausl.mo.it

\section{ABSTRACT}

Background and study aims We report on a case of a traumatic rectal perforation that occurred in a 16-year-old girl, which was successfully treated using an over-the-scope clip, avoiding major surgery and stoma.

\section{Introduction}

The over-the-scope clip (OTSC) (Ovesco Endoscopy GmbH, Tübingen, Germany), designed for tissue approximation, is already recommended as first-line endoscopic treatment for endoscopic acute iatrogenic perforation [1]. To the best of our knowledge, no data regarding gastrointestinal traumatic, not iatrogenic, perforation repaired with the use of OTSC, are available.

\section{Case report}

A 16-year-old girl was referred to the emergency room for copious rectal bleeding and secondary syncope, due to violent trauma. Computed tomography (CT) scan and subsequent colonoscopy revealed a voluminous pelvic hematoma and a $35-$ to $40-\mathrm{mm}$ irregular full-thickness defect, located in the posterior rectal wall, about $30 \mathrm{~mm}$ from the dentate line ( $\bullet$ Fig. $\mathbf{1})$.

Because of the lesion's features and the acute setting, an OTSC was placed $(12 / 6 \mathrm{~mm}$, traumatic type) using the OTSC twin grasper (Ovesco Endoscopy $\mathrm{GmbH}$, Tübingen, Germany) ( $\bullet$ Fig.2). This auxiliary device has two jaws which can be opened separately, allowing better gaping edges approximation.

The entire procedure was performed under deep sedation, using $\mathrm{CO}_{2}$ insufflation > Video 1 .

The endoscopic treatment was effective, as confirmed after contrast medium injection and CT scan.

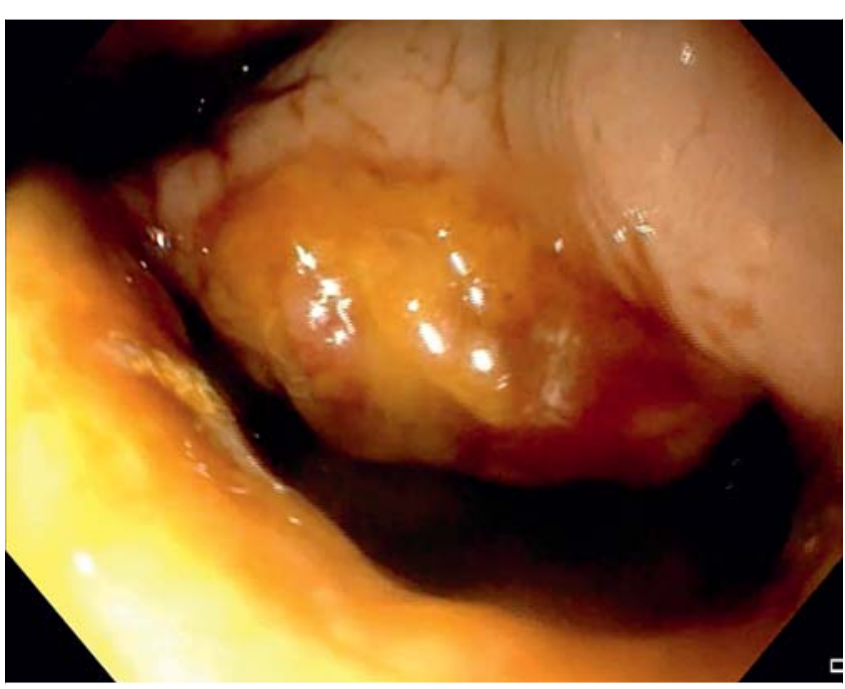

Fig. 1 35- to 40-mm irregular full-thickness defect of the posterior rectal wall.

A Few days later, second endoscopic look confirmed complete sealing of the defect and the patient was discharged home ( Fig. 3). 


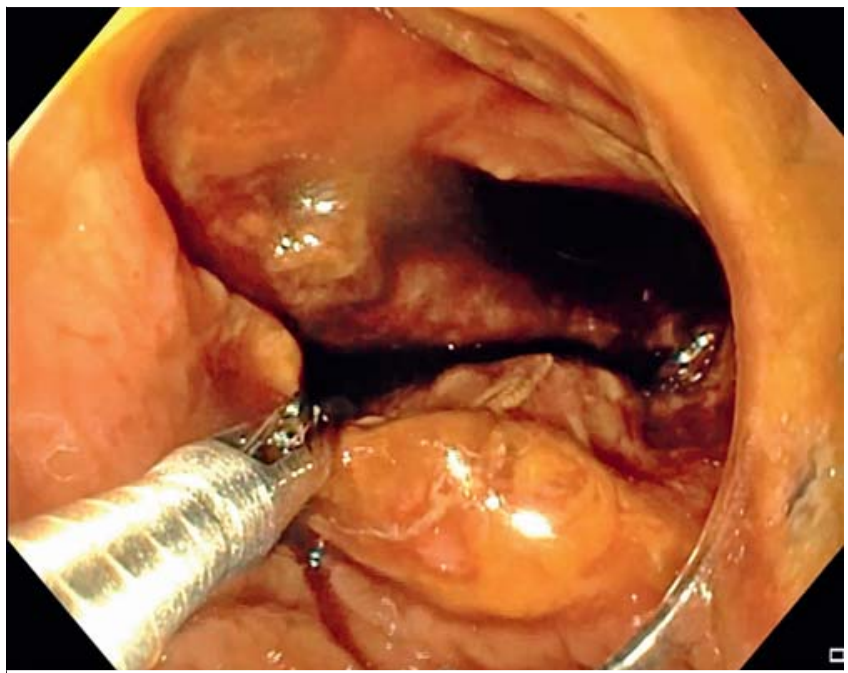

- Fig. 2 Edges approximation with OTSC twin grasper.

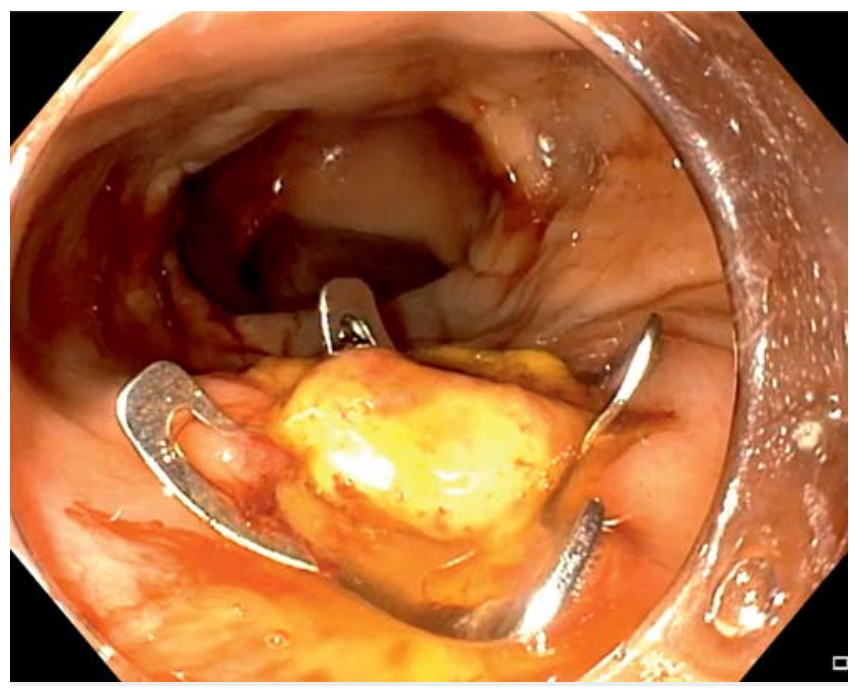

Fig. 3 Complete sealing of the defect.

\section{Conclusion}

In conclusion, OTSC with a twin grasper can successfully treat wide traumatic rectal perforation, avoiding major surgery with definitive or temporary stoma, especially in a young patient.

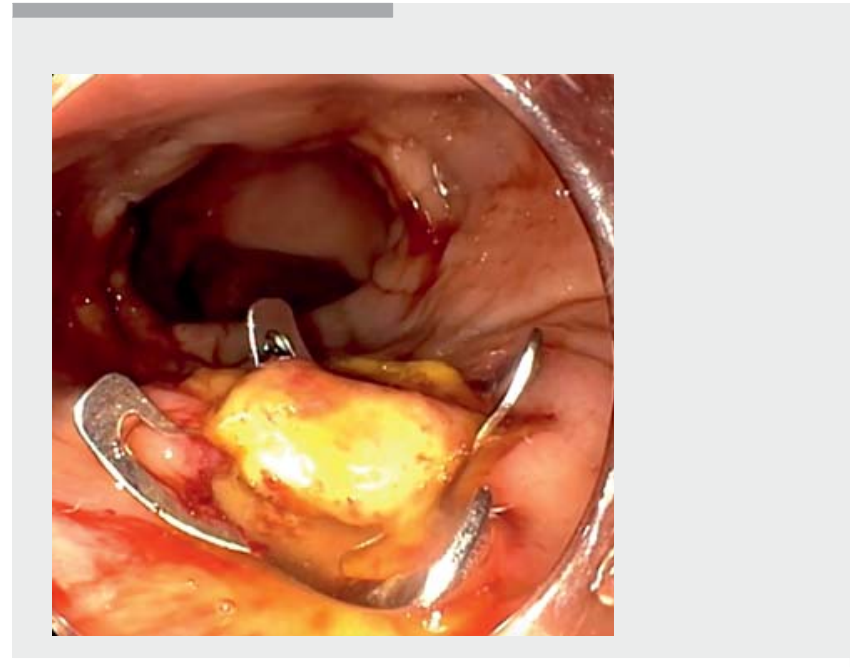

$\nabla$ Video 1 Full-length video showing the entire successful repair of wide traumatic rectal perforation using OTSC

\section{Competing interests}

The authors declare that they have no conflict of interest.

Reference

[1] Paspatis GA, Dumonceau JM, Barthet M et al. Diagnosis and management of iatrogenic endoscopic perforations: European Society of Gastrointestinal Endoscopy (ESGE) Position Statement. Endoscopy 2014; 46: 693-711 